\title{
Flax Seeds and Finger Millet Enriched Functional Rusk
}

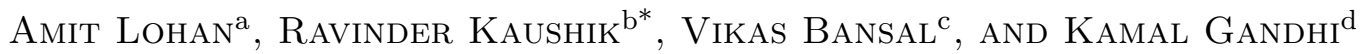 \\ a Amity University, Jaipur-302017, Rajasthan India \\ b Amity University, Noida-201313, Uttar Pradesh, India \\ c Jaipur National University, Jaipur-302017, Rajasthan, India \\ d National Dairy Research Institute, Karnal-132001, India \\ *Corresponding author \\ ravinder_foodtech2007@rediffmail.com \\ TEL: +91-9416962729(M)
}

Received: 22 November 2018; Published online: 18 April 2020

\begin{abstract}
Bakery products are generally made up of refined wheat flour that may be deficient in both fibre and essential fatty acids. In this study $\alpha$-linolenic acid and fibre enriched rusk using flax seeds and finger millet were developed. The proportions of finger millet, flax seed and wheat flours were optimized using Response Surface Methodology (RSM). On the basis of fibre and ALA content and baking quality characteristics of rusk $13.13 \%, 6.0 \%$ and $80.6 \%$ of finger millet, flax seed and wheat flours, respectively was finalized. The developed rusk contained $4.81 \%$ fibre and $1.36 \% \alpha$-linolenic acid. Wet and dry gluten content, SDS sedimentation, falling number, dough raising capacity of yeast and baking time of mixed flour of these components were statistically $(\mathrm{p}>0.05)$ similar to that of wheat flour (control). However, higher loaf weight and lower loaf height was observed in mixed flour rusk in comparison to control rusk. $\alpha$-linolenic acid and fibres enriched rusk were developed with similar quality parameters and improved functional properties.
\end{abstract}

Keywords: Fortification; Flax seeds; Finger millet; Rusk; $\alpha$-linolenic acid

\section{Introduction}

The baking Industry is the largest organized sector within the Indian Food Industry (Nasirullah, Marry \& Shariff, 2013). With wheat reported as the most popular cereal grain for baked goods. The elasticity of wheat dough and its rheological properties make wheat superior to other cereal grains (Kaushik et al., 2013). The major factor sought for the suitability of wheat varieties for making different types of bakery products is the ability of the flour used to form a gluten network (Kumar, Khatkar \& Kaushik, 2013).which is the protein component of flour that gives the dough elasticity and strength (Sharma, Khatkar, Kaushik, Sharma \& Sharma, 2017). In wheat products such as bread, the gluten network formation is desirable for gas retention that in turn enhances the volume of product, while in products such as biscuits, extensibility is required, so gluten formation and its gas retention network is undesirable. Getting the desired quality of wheat flour for making specific kinds of bakery products is a challenging task for the bakery industry (Kaushik, Chawla, Kumar, Janghu \& Lohan, 2018; Kaushik, Chawla, Kumar \& Kumar, 2017).

The rusk is a bakery product that has low residual moisture and is rapidly soluble in warm liquids (Liu, Bates, Yin, Wang \& Lu, 1993). Williams (1976) defined the rusk as any cooked product of a grain based dough, whether it has been raised with yeast or not. Rusks are formed 
when bread is baked twicee and these are generally made by baking leavened bread in small portions and then reducing the baked bread to crumbs. The most commonly used grains is wheat, however maize and barley grains may be used. Rusk is widely consumed in all countries, the production procedure includes mixing, fermentation, baking and roasting (Yaseen, 2000). Mallik and Kulkarni (2010) prepared rusk by replacing water with concentrated whey. The rusk produced showed good appearance, flavour, body and texture and overall acceptability during storage $\left(37^{\circ} \mathrm{C}\right)$ for 9 days. Nasirullah et al. (2013) determined the physicochemical characteristics of fat present in rusk and reported 5.8 $\%$ fat, 53.5 butyrometer reading (BR), $31.5{ }^{\circ} \mathrm{C}$ slip melting point and 73.5 Iodine value (IV). Liu et al. (1993) checked/determined / characterized the nutritional efficacy of a fortified weaning rusk thrhuman trails on 2026 full term infants (6-13 months). Rusks were fortified with zinc, iron, calcium, vitamin A, D, B12, thiamin, riboflavin, niacin and folic acid. Infants who received fortified rusks exhibited no decline in haemoglobin concentrations during 3 months study.

Fortification of diets with food materials rich in bioactive compounds were shown to impart several health benefits that can be exploited in development of health foods (Devi, Vijayabharathi, Sathyabama, Malleshi \& Priyadarisini, 2014). F seed consumption increased due to its potential functional properties on health (Carraro, de Souza Dantas, Espeschit, Martino \& Ribeiro, 2012). Flax seed oil is rich in omega-3 ( $\alpha$ linolenic acid), digestible proteins and soluble fibre (lignin). Pohjanheimo, Hakala, Tahvonen, Salminen and Kallio (2006) reported that with addition of flaxseed, the bread improves moisture retention and softness of bread without any off order (rancidity and mustiness) up to 6 days storage. They further reported a positive impact of flaxseed on textural properties of bread during storage along with improvement in nutritional composition (fibre and $\alpha$-linolenic acid). Finger millet is one of the minor cereals known for several health benefits such as anti-diabetic, antitumerogenic, anti-diarrheal, antiulcer, antiinflammatory, atherosclerogenic effects, antioxidant and antimicrobial properties (Chandra, Chandra, Pallavi \& Sharma, 2016). Finger mil- let contains several phenolic acids and their derivatives, flavonoids and tannins, and showed multifunctional activity and free radical terminator, metal chelator, and singlet oxygen quencher properties. Hegde, Anitha and Chandra (2005) reported that whole finger millet meal flour protected wistar rats against hyperglycaemic and alloxan- induced oxidative stress.

Therefore, the present study was designed for development and evaluation of finger millet and flaxseed enriched rusk to develop new healthy bakery products. The optimization was carried out using Response Surface Methodology. (RSM)

\section{Materials and Methods}

\subsection{Materials}

Wheat cultivar C-306, and finger millet were procured form a Wheat Breeding Farm, Haryana Agriculture University, Hisar, India. Flax seeds, sugar, salt, shortening and baker's yeast (Saccharomyces cerevisae) were procured from a local market, Hisar, India. Airtight plastic containers were used for grain storage and flour storage. Parad tablets (Himalya, India) were put into grains container enclosed in cloth for protection of wheat grains during storage.

\subsection{Milling of wheat, finger millet and flex seeds}

Clean wheat and finger millet grains were conditioned by steeping the grains in hot water $(60$ ${ }^{\circ} \mathrm{C}$ ) for $4 \mathrm{~h}$. The water was drained off and grains were dried in sunlight. The moisture content was adjusted by tempering the grains to $16 \%$. The above conditioned wheat and finger millet were milled using a roller-mill (Chopin Laboratory CD-1 mill, France). Flax seeds were milled without any conditioning treatment and the flour obtained was stored in airtight plastic containers under ambient conditions for further analysis. To ensure the purity of the roller-milled flour samples from each lot, mechanical and manual cleaning of the roller-mill, including air was performed between milling of each sample. 


\subsection{Proximate Analysis}

Wheat, finger millet and flex seed flour obtained were then analysed for moisture, ash, protein and fat contents using Official Methods of Analysis of the Association of Official Analytical Chemists (2012). The $\alpha$-linolenic acid was determined using method no. 2012.13 (Official Methods of Analysis of the Association of Official Analytical Chemists, 2012) and total dietary fibre content was determined using method no. 991.43 (Official Methods of Analysis of the Association of Official Analytical Chemists, 2012).

\subsection{Quality characteristics of wheat flour}

Quality characteristics of wheat flour was determined using wet and dry gluten yield, gluten index, SDS sedimentation value and falling number. Gluten extraction was carried out by adopting the procedure as described by Kumar et al. (2013). Wet gluten yield, gluten index and dry gluten yield was determined as per method described by Kaushik et al. (2013). The falling number and dough rising capacity were determined by the approved method as described by AACC (2012) and the results were expressed as time in seconds. Sodium dodecyl sulphate (SDS Solution) sedimentation volume of flour samples was estimated according to the method as described by Axford, McDermott and Redman (1978).

\subsection{Optimization of ingredients and rusk preparation}

The Straight dough method was used for preparation of dough. The ingredients composition (formula) used was according to the experimental runs given by the Box-Behnken design of Response Surface Methodology (RSM) within the range as wheat (90 to $100 \mathrm{~g}$ ), finger millet (0 to $10 \mathrm{~g}$ ) and flax seeds flour (2 to $6 \mathrm{~g}$ ). Salt, water, yeast, sugar and fat were added at the rate of $1.0,48.0,7.5,28.0$ and $2.0 \%$ of flour, respectively. The concentration of different ingredients taken for optimization was selected on the basis of pre-analysis and literature reviewed for the preparation of rusk.

A second order polynomial equation was used to express the responses as a function of the independent variables given below:

$Y_{k}=\beta_{k 0}+\sum_{i=1}^{n} \beta_{k i} X_{i}+\sum_{i=1}^{n} \beta_{k i i} X_{i}^{2}+\sum_{i=1}^{n-1} \sum_{j=i+1}^{n} \beta_{k i j} X_{i} X_{j} \quad$ (1)

where $\mathrm{Y}_{k}=$ response variable; $\mathrm{Y}_{1}=$ Fat content $(\%) ; \mathrm{Y}_{2}=$ Yeast (\%); $\mathrm{Y}_{3}=$ Sugar content $(\%) \mathrm{Y}_{4}=$ water content $(\%) ; \mathrm{x}_{i}$ represent the coded independent variables $\left(\mathrm{x}_{1}=\right.$ wheat flour content $(\mathrm{g}), \mathrm{x}_{2}=$ finger millet flour content $(\mathrm{g})$, $\mathrm{x}_{3}=$ flax seed flour $(\mathrm{g})$; where $\beta_{k o}$ was the value of the fitted response at the centre point of the design, i.e., point $(0,0,0), \beta_{k i}, \beta_{k i i}$ and $\beta_{k i j}$ were the linear, quadratic and cross-product regression coefficients, respectively. The test of statistical significance was performed on the total error criteria, with a confidence level of $95 \%$.

The significant terms in the model were found by analysis of variance (ANOVA) for each response. The adequacy of the model was checked by calculating the $\mathrm{R}^{2}$ and adjusted- $\mathrm{R}^{2}$. The numerical optimization techniques of the Design-Expert software were used for the simultaneous optimization of the multiple responses. The desired goals for each variable and response were chosen. All of the independent variables were kept within range, while the responses were either maximized or minimized. Optimization of ingredients data using RSM is presented in table 1 .

\subsection{Rusk preparation}

Rusks were prepared using method as described by Yaseen (2000) with some modifications. Yeast and water were mixed in a bowl and kept it for 30 min then sugar was added for activation of yeast and. Flour and other ingredients except fat were added to the yeast water solution. Fat was added in last. Mixing was carried out for 10-12 min. Two stage proofing was carried out. First proofing for 105 minutes, knock back and a further 45 minutes second proofing. Baking was done at $200{ }^{\circ} \mathrm{C}$ for 15 minutes and the loaf was left to cool overnight. The next day, the loaf was sliced and then baked a second time at $160{ }^{\circ} \mathrm{C}$ for 20 minutes and finally the prepared rusks were 
Table 1: Box-Behnken Design arrangement and percentage of ingredient

\begin{tabular}{llllllllll}
\hline Std & Run & X1 & X2 & X3 & Salt 1\% & Fat $2 \%$ & Yeast $7.5 \%$ & Sugar $28 \%$ & Water $48 \%$ \\
\hline 15 & 1 & 95 & 5 & 4 & 1.04 & 2.08 & 7.80 & 29.12 & 49.92 \\
8 & 2 & 100 & 5 & 6 & 1.11 & 2.22 & 8.33 & 31.08 & 53.28 \\
13 & 3 & 95 & 5 & 4 & 1.04 & 2.08 & 7.80 & 29.12 & 49.92 \\
12 & 4 & 95 & 10 & 6 & 1.11 & 2.22 & 8.33 & 31.08 & 53.28 \\
14 & 5 & 95 & 5 & 4 & 1.04 & 2.08 & 7.80 & 29.12 & 49.92 \\
4 & 6 & 100 & 10 & 4 & 1.14 & 2.28 & 8.55 & 31.92 & 54.72 \\
2 & 7 & 100 & 0 & 4 & 1.04 & 2.08 & 7.80 & 29.12 & 49.92 \\
6 & 8 & 100 & 5 & 2 & 1.07 & 2.14 & 8.03 & 29.96 & 51.36 \\
3 & 9 & 90 & 10 & 4 & 1.04 & 2.08 & 7.80 & 29.12 & 49.92 \\
5 & 10 & 90 & 5 & 2 & 0.97 & 1.94 & 7.28 & 27.16 & 46.56 \\
9 & 11 & 95 & 0 & 2 & 0.97 & 1.94 & 7.28 & 27.16 & 46.56 \\
10 & 12 & 95 & 10 & 2 & 1.07 & 2.14 & 8.03 & 29.96 & 51.36 \\
16 & 13 & 95 & 5 & 4 & 1.04 & 2.08 & 7.80 & 29.12 & 49.92 \\
17 & 14 & 95 & 5 & 4 & 1.04 & 2.08 & 7.80 & 29.12 & 49.92 \\
7 & 15 & 90 & 5 & 6 & 1.01 & 2.02 & 7.58 & 28.28 & 48.48 \\
1 & 16 & 90 & 0 & 4 & 0.94 & 1.88 & 7.05 & 26.32 & 45.12 \\
11 & 17 & 95 & 0 & 6 & 1.01 & 2.02 & 7.58 & 28.28 & 48.48 \\
\hline
\end{tabular}

Where: X1- Factor 1A: wheat flour (g), X2-Factor 2 B: finger millet (g), X3-Factor 3 C: flax seed (g)

packed in polyethylene packs and stored at room temperature for further processing.

\subsection{Sensory evaluation}

Sensory evaluation of rusk was carried out using a nine (9) point Hedonic scale with 1 indicating an extremely disliked and 9 indicating an extremely liked sample. Sample scoring a mean value of 6 and above were taken as acceptable (Ranganna, 1986). Test panel composition and procedures were approved for sensory analysis by the ethics committee, Shoolini University, Solan. The samples were evaluated by the panels for colour, taste, appearance and overall acceptability. The panel scored quality characteristics of each sample using preference test on a nine point hedonic scale as previously described. The sample with highest mean score for all characteristics was chosen to be the most preferred one. The sensory evaluation of the rusk was performed with an evaluation panel of 10 trained members.

\subsection{Textural Properties of rusk}

Rusk hardness/crispiness was determined with a Texture Analyser TAXT2i (Stable Micro Systems Ltd., Surrey, UK) equipped with a $25 \mathrm{~kg}$ load cell in compression mode with a Knife Edge (HDP/BS) attached to the load cell carrier and lowered into the slotted insert. The Heavy Duty Platform (HDP/90) was repositioned so that there was no contact between the blade and slot surfaces and a 'blank' test run as a check. The blade was then raised to allow placement of the sample. Pre- and post-test speeds were 1.5 and $10 \mathrm{~mm} / \mathrm{s}$, respectively while test speed was 2.0 $\mathrm{mm} / \mathrm{s}$. The maximum force reading (i.e. highest peak) was observed within the first seconds of the test. At this point the rusk fractured into two large pieces. Hardness of rusk $(n=8)$ was determined after 30 minutes of second baking.

\subsection{Physical measurements}

The time required for first and second baking was recorded in minutes. Volumes of cooled loaves 
were measured by the rape seed displacement method. Specific volumes were calculated from loaf volume and loaf weight taken after $1 \mathrm{~h}$ of baking (Yaseen, 2000).

\subsection{Statistical analysis}

The data was analysed using the method described by Kaushik, Sachdeva and Arora (2014). Means, standard error of the mean (SEM), linear regression analysis and 95\% confidence intervals were calculated using Microsoft Excel 2007 (Microsoft Corp., Redmond, WA). Data was subjected to a single way analysis of variance (ANOVA) to calculate critical difference.

\section{Results and discussion}

Finger millet and flax seed flour along with refined wheat flour were used for the preparation of rusks containing high fibre content and $\alpha$ linolenic acid, respectively. Three types of flours in different proportions were used during trials for preparation of the rusk and finally a range was fixed for each type of flour on the basis of characteristic properties required for dough preparation. Response Surface Methodology was used for optimization of the best combination containing maximum fibre and $\alpha$-linolenic acid content. The physicochemical properties of all three types of flours used for rusk preparation were determined and represented as below:

\subsection{Proximate analysis of flour samples}

The moisture content was significantly higher in finger millet, and lowest in flax seed flour. Moisture content is an important factor as it affects the water activity which in turn affects the microbial proliferation and oxidative degradationJanghu, Ray, Bansal and Kaushik (2014). Fat content of flax seed was highest (37.10\%), and lowest in refined wheat flour $(0.40 \%)$. Flax seed showed higher protein content, while finger millet showed lowest protein content. Moreover, ash content was highest in finger millet, and lowest in refined wheat flour. Flax seed showed highest amount of fibre content, while refined wheat flour showed least amount of fibre content (Table 2). We could not use higher amount of flax seed flour due to its fat content which restricted the development of gluten networks in the dough. The main purpose of including the flaxseed flour was its higher content of $\alpha$-linolenic acid content which was not detected in wheat and finger millet flour, respectively.

\section{Effect of different flours on fibre content}

The fibre content in different rusk samples ranged between 4.1 to $5.36 \mathrm{~g}$ with an average value of $4.69 \mathrm{~g}$, respectively (Table 3 ). High fibre content exhibit important role in lowering serum cholesterol and glucose level, and essential for intestinal health (Miremadi, Sherkat \& Stojanouska, 2016). The interactive effect of flours on fibre content have been shown in $3 \mathrm{D}$ graphs of figure 1(a) which indicates that variation in proportions of millet flour and flaxseed flour showed great effect on fibre content as compare with refined wheat flour. The fibre content was found to be increased with increasing proportion of finger millet and flaxseed flour in the mixture of flour, however increasing the proportion of refined wheat flour did not affect the fibre content. The reason behind this was low fibre content of refined wheat flour as compare with finger millet and flaxseed flour.

\section{Effect of flours amount on $\alpha$-linolenic acid content:}

$\alpha$ - linolenic acid in different rusk samples ranged in between 0.531 to $1.355 \mathrm{~g}$ with an average value of $0.889 \mathrm{~g}$ (Table 3). The variation of $\alpha$-linolenic acid was mainly due to level of addition of flaxseed flour, so varied proportion of flaxseed flour showed significant effect on the $\alpha$-linolenic acid content of rusk. Increased proportion of wheat and finger millet flour keeping the flaxseed flour constant lowered the $\alpha$-linolenic acid content and vice versa (figure $1 \mathrm{~b}$ ). 
Table 2: Chemical Composition of Raw Materials

\begin{tabular}{lcccccc}
\hline Sample & $\begin{array}{c}\text { Moisture } \\
(\%)\end{array}$ & $\begin{array}{c}\text { Fat } \\
(\%)\end{array}$ & $\begin{array}{c}\text { Protein } \\
(\%)\end{array}$ & $\begin{array}{c}\text { Ash } \\
(\%)\end{array}$ & $\begin{array}{c}\text { Fibre } \\
(\%)\end{array}$ & $\begin{array}{c}\text { ALA } \\
(\mathrm{mg} / \mathrm{g})\end{array}$ \\
\hline Wheat Flour & $12.8 \pm 0.92^{b}$ & $0.40 \pm 0.02^{a}$ & $11.20 \pm 0.81^{b}$ & $0.50 \pm 0.04^{a}$ & $2.7 \pm 0.54^{a}$ & ND \\
Finger millet & $13.20 \pm 0.79^{b}$ & $1.30 \pm 0.57^{b}$ & $7.30 \pm 0.45^{a}$ & $4.00 \pm 0.13^{c}$ & $4.5 \pm 0.67^{b}$ & ND \\
Flax Seeds & $6.50 \pm 0.65^{a}$ & $37.10 \pm 1.21^{c}$ & $20.30 \pm 0.78^{c}$ & $3.50 \pm 0.20^{b}$ & $8.12 \pm 0.58^{c}$ & $230.63+4.7$ \\
\hline
\end{tabular}

$\mathrm{ALA}=$ Alpha Linolenic Acid; ND= Not Detected

Data are presented as mean $\pm \operatorname{SEM}(n=3)$.

${ }^{a-b}$ Means with same superscript in column do not vary significantly $(\mathrm{p}<0.05)$ from each other.

Table 3: Box Behnken design experiments for optimization of flour amount

\begin{tabular}{lllll}
\hline & \multicolumn{2}{c}{ Independent Variables } & \multicolumn{2}{c}{ Dependent Variables } \\
Wheat flour $(\mathrm{g})$ & Finger millet flour $(\mathrm{g})$ & Flaxseed flour $(\mathrm{g})$ & Fibre content $(\mathrm{g})$ & ALA $(\mathrm{g})$ \\
\hline 100 & 10 & 4 & 4.77 & 0.9 \\
90 & 15 & 4 & 4.66 & 0.86 \\
90 & 20 & 6 & 4.95 & 1.241 \\
90 & 10 & 2 & 4.37 & 0.555 \\
80 & 15 & 4 & 4.38 & 1.355 \\
80 & 10 & 6 & 4.10 & 0.94 \\
90 & 10 & 2 & 4.37 & 1.31 \\
90 & 2 & 4.95 & 0.552 \\
100 & 20 & 6 & 5.06 & 0.535 \\
100 & 15 & 2 & 5.06 & 1.211 \\
80 & 15 & 4 & 4.38 & 0.531 \\
90 & 15 & 4 & 4.68 & 0.85 \\
90 & 15 & 4 & 4.72 & 0.852 \\
80 & 15 & 4 & 4.68 & 0.88 \\
100 & 20 & 4 & 5.36 & 0.838 \\
90 & 20 & 4 & 4.64 & 0.855 \\
90 & 15 & & 4.65 & 0.858 \\
\hline
\end{tabular}

\subsection{Optimization of flour amounts}

Optimum amount of flour samples were tested to obtain the criteria of maximum fibre and $\alpha$ linolenic acid content (Table 3). Second order polynomial models were used for each response to determine the optimum flour amount of samples. The optimization was applied on selected range of wheat, finger millet and flax seed flour samples as $80-100,10-20$, and $2-6 \mathrm{~g}$, respectively. The desirability function method was used to obtain the optimum amount of flour in the mixture. This method gave the desirability value of $0.891 \mathrm{~g}$ with amount of flours as $80.06 \mathrm{~g}$ for wheat, $13.13 \mathrm{~g}$ for finger millet, and $6.0 \mathrm{~g}$ for flaxseed. By using these proportions of flour, $4.81 \mathrm{~g}$ of fibre and $1.358 \mathrm{~g}$ of $\alpha$-linolenic acid were predicted. Small deviations were recorded between the experimental and predicted values, therefore, the model obtained in this study could be utilized to optimize the flour amounts. 
Functional rusk $\mid 219$

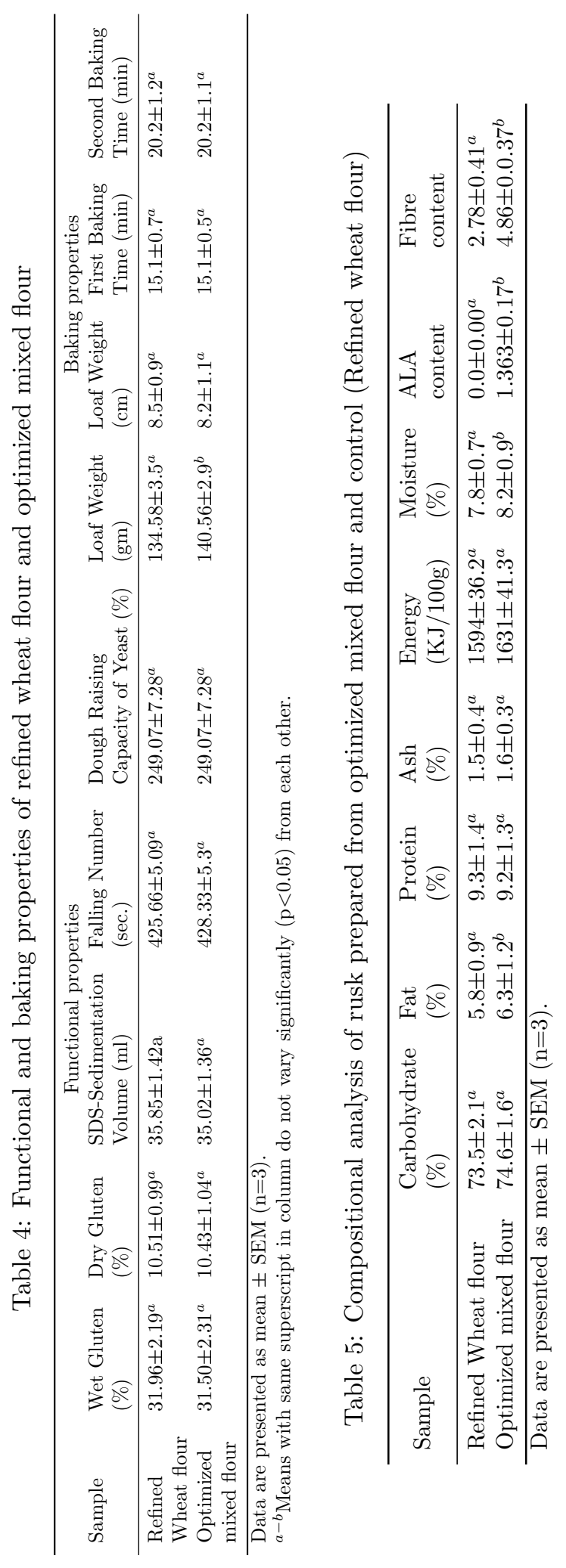

IJFS | April 2020 | Volume 9 | pages 213-224 

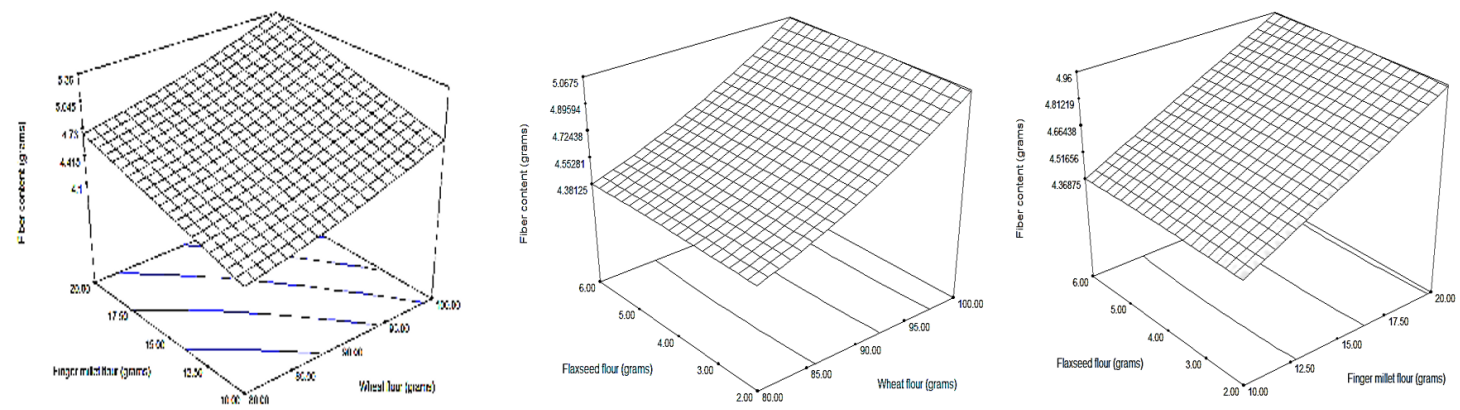

(a)
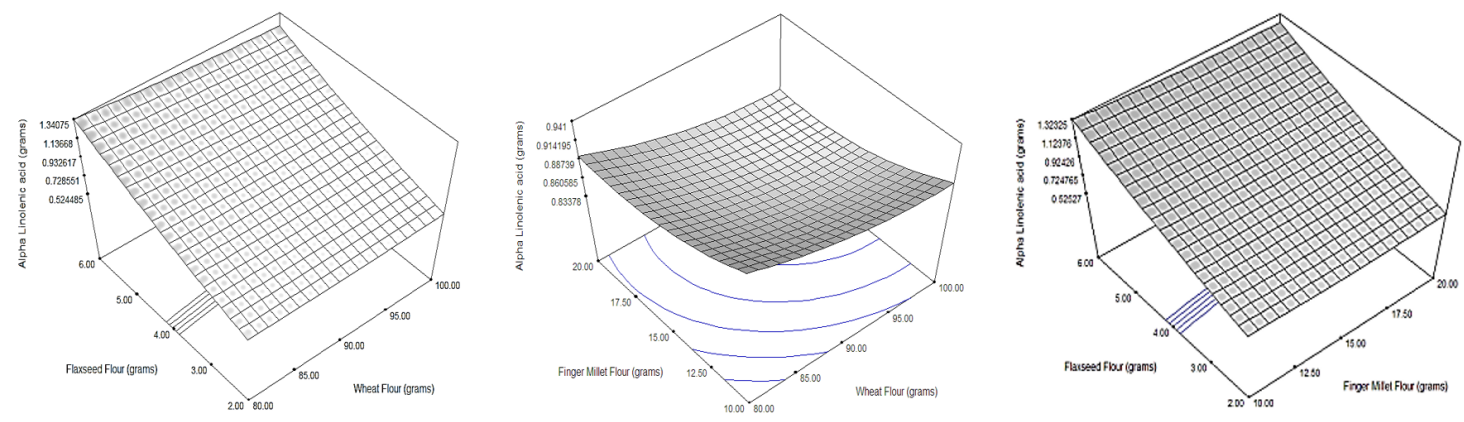

(b)

Figure 1: (a) Effect of different amount of flour on fiber content (b) Effect of different amount of flour on Alpha Linolenic acid content.

Table 6: Sensory properties and cost of rusk prepared from optimized mixed flour and control (Refined wheat flour)

\begin{tabular}{|c|c|c|c|c|c|c|}
\hline \multirow{2}{*}{ Sample } & \multicolumn{5}{|c|}{ Sensory analysis of rusk (9 point hedonic scale) } & \multirow{2}{*}{$\begin{array}{l}\text { Cost of } \\
\text { production } \\
\text { (in Rs) }\end{array}$} \\
\hline & Colour & Texture & Crispiness & Taste & $\begin{array}{l}\text { Overall } \\
\text { acceptability }\end{array}$ & \\
\hline Refined wheat flour (Control) & $8.21 \pm 0.08^{a}$ & $7.91 \pm 0.13^{b}$ & $7.79 \pm 0.08^{b}$ & $8.09 \pm 0.08^{a}$ & $8.04 \pm 0.10^{a}$ & 47.29 \\
\hline Optimized Mixed flour & $7.90 \pm 0.05^{b}$ & $8.10 \pm 0.14^{a}$ & $8.30 \pm 0.12^{a}$ & $8.10 \pm 0.09^{a}$ & $8.10 \pm 0.06^{a}$ & 50.46 \\
\hline
\end{tabular}

Data are presented as mean \pm SEM $(n=3)$. 


\subsection{Comparison of optimized flour mixture with control flour for functional parameters}

The optimized flour mixture was compared with control (only refined wheat flour) for preparation of rusks and its quality characteristics. The results obtained are presented in Table 4 and discussed as follows:

The functional testing values of the raw component material i.e. wheat flour and yeast were studied. Wet and dry gluten yield of refined wheat flour was 31.96 and $10.51 \%$ while of optimized mixed flour was 31.50 and $10.43 \%$, respectively. There was non-significant difference in between these values as the lesser protein content of finger millet flour was compensated by higher protein content of flaxseed flour. Our observations were in accordance with Singh and Singh (2006) and Kaushik et al. (2013). The wet and dry gluten yield indicates the quality of protein and baking quality of flour.Autran, Hamer, Plijter and Pogna (1997) observed that pentosans and hemicelluloses in flours have a strong effect on gluten yield and that flour processing properties are strongly determined by the way flour milling fractions are blended. SDS values and Falling number for refined wheat and optimized mixed flour were $35.85 \mathrm{ml}, 425.66 \mathrm{~s}$ and $35.02 \mathrm{ml}, 428.33$ $\mathrm{s}$, respectively. Similar to protein content, no significant difference was obtained between these values of SDS and falling number value. Present SDS values were in agreement with the values obtained by Supekar, Patil and Munjal (2005) and Kaushik et al. (2014). The SDS sedimentation value of wheat flours is based on the fact that the gluten protein absorbs water and swells considerably when treated with lactic acid. Falling number indicates flour quality. More the falling number low will be the amylase activity and vice-versa. According to AACC (2012) high falling number $(>300 \mathrm{~s})$ indicates minimal enzyme activity and sound quality of wheat flour. A low falling number $(<250 \mathrm{~s})$ indicates substantial enzyme activity and sprout-damaged wheat or flour. Dough raising capacity of yeast was $249.07 \%$.

\subsection{Baking quality characteristics of rusk}

Rusks prepared with incorporation of finger millet flour and flax seed flour were analysed for their baking quality characteristics and compared with the control sample (refined wheat flour) which is presented in Table 4. Weight and height of the prepared loaves were measured just before second baking of rusk. In the case of the refined wheat flour dough before baking, the initial dough weight was $148 \mathrm{~g}$ which reduced to $134.58 \mathrm{~g}$, while in case of mixed flour it reduced from $156 \mathrm{~g}$ to $140.56 \mathrm{~g}$, respectively. During the experiment where the concentration of fibre material was increased i.e. flax seed, the weight of loaf samples also increased and the reason behind this was the high fibre content in the flax seeds. The fibre content has strong water binding ability which results in more water absorption. So high water retention causes increase in bread weight (Chen, Ratnayake \& Cunnane, 1994). Loaves height was observed to reduce from 8.5 to $8.2 \mathrm{~cm}$ in refined wheat flour and mixed flour dough, respectively. The variation in height was due to the quantity of the wheat flour used. It was observed that due to the gluten network the height of loaf increased when the wheat flour concentration was increased. It was found that the samples with high concentration of wheat flour produced a better gluten network, and hence resulted in more puffing and good height. The baking time was kept constant for both samples as first baking was lasted for 15 min and second for $20 \mathrm{~min}$, respectively.

\subsection{Compositional characteristics of rusk}

Non-significant difference was observed in the composition of rusk prepared from both type of flours i.e. refined wheat and optimized mixed flour. The results of nutritional composition i.e. moisture, carbohydrates, protein, fat, ash and energy were presented in Table 5 . Table 5 showed that that rusks prepared from mixed flour contain similar carbohydrate, protein, ash and energy in comparison to control wheat rusks, however, significantly higher fat, moisture, ALA and 
fibre contents compared to that of refined wheat flour were observed. The reason of high fat was the incorporation of flaxseed flour which is a rich source of fat and this high fat content was also responsible for slightly higher energy value of these rusks as fat provides $9 \mathrm{Kcal} / \mathrm{g}$ energy after metabolism in the body. The higher moisture content in the mixed flour rusks was due to the high fibre content that has the ability to absorb moisture. This is because of the lack of expansion of gas bubble to their full potential due to rupture of cell walls by fibre particles (Lue, Hsieh \& Huff, 1991). No ALA was detected in the control Rusk. The ALA content of the optimized mixed flour rusk was significantly $(\mathrm{p}<0.05)$ higher than control. Similarly, significantly $(\mathrm{p}<0.05)$ higher fibre content was observed in optimized mixed flour rusk in comparison to control. It was also observed that both ALA and fibres were stable in rusks after baking, however, slightly higher content was observed due to decrease in moisture content. Ratnayake et al. (1992) determined the thermal stability of flaxseed oil upon $350{ }^{\circ} \mathrm{C}$ and also oxidative stability up to 10 months and reported that the oil was heat and oxidative stable. Similar results were also reported by Chen et al. (1994) and Cunnane et al. (1995). Fibres are highly stable components and its stability during baking was reported by several researchers. Rupasinghe, Wang, Huber and Pitts (2008) reported that fibres were stable after baking of muffins.

\subsection{Sensory analysis of rusk}

Control rusks and optimized mixed flour rusks were compared for sensory acceptability and results are presented in Table 6. It was observed that Optimized mixed flour rusks obtained significantly $(\mathrm{p}<0.05)$ lower scores for colour in comparison to control rusks. It may be due to dark colour of flaxseed and finger millet, however in texture, crispiness, taste and overall acceptability mixed flour rusks showed higher sensory scores than that of control. The sensory scores revealed that rusks prepared from the mixed flour sample was superior the control rusks. Rusks are a highly consumable bakery product among the poor and middle class people. They are comparatively simple and inexpensive to prepare when compared to other bakery items. The cost of mixed flour rusks were higher than control sample as finger millet and flaxseed flour cost was higher than that of wheat flour. The cost of control rusk and mixed flour rusk were 47.29 and 50.46 rupees per unit or kilogram, respectively. The cost of mixed flour rusk was slightly higher, but it supplies ALA and higher fibres in comparison to control rusk. Therefore, consumers can spent even more to buy such health beneficial rusk.

\section{Conclusions}

It has been observed that the developed rusks were a good source of fibre and $\alpha$-linolenic acid with excellent processing and storage stability. With time the market demand changes which, leads to new and innovative products. Traditional food could, be replaced by reformulated traditional functional food products which, in the present study was achieved with finger millet and flax seeds. The enriched Rusks have similar quality characteristics and sensory properties as the control sample and potentially provide more variety and health attributes to the human population. Also, there is need of such products in the market as the burden of disease is increasing day by day. Mineral fortification and essential amino acids addition to other rusks will also be carried on in future research.

\section{Acknowledgements}

The authors acknowledge the financial support provided by Department and University for providing all chemicals, glassware and instruments.

\section{References}

AACC. (2012). Approved Methods of Analysis, 11th Ed. Method 56-81.04. Determination of Falling number. St. Paul, MN, U.S.A. Retrieved from http://methods.aaccnet. org/summaries/56-81-04.aspx 
Autran, J. C., Hamer, R. J., Plijter, J. J. \& Pogna, N. E. (1997). Exploring and improving the industrial use of wheats. Cereal Foods World, 42(4), 216-227. Retrieved from https : / / www . researchgate . net / publication / $287559740 \%$ 20_Exploring_and_improving_ the_industrial_use_of_wheats

Axford, D. W. E., McDermott, E. E. \& Redman, D. G. (1978). Small scale tests of bread making quality. Milling Feed Fert.

Carraro, J. C. C., de Souza Dantas, M. I., Espeschit, A. C. R., Martino, H. S. D. \& Ribeiro, S. M. R. (2012). Flaxseed and human health: Reviewing benefits and adverse effects. Food Reviews International, 28(2), 203-230. doi:10 . 1080 / 87559129 . 2011.595025. eprint: https://doi.org/10. 1080/87559129.2011.595025

Chandra, D., Chandra, S., Pallavi \& Sharma, A. K. (2016). Review of finger millet (eleusine coracana (1.) gaertn): A power house of health benefiting nutrients. Food Science and Human Wellness, 5(3), 149155. doi:10.1016/j.fshw.2016.05.004

Chen, Z. Y., Ratnayake, W. M. N. \& Cunnane, S. C. (1994). Oxidative stability of flaxseed lipids during baking. Journal of the American Oil Chemists Society, 71(6), 629-632. doi:10.1007/BF02540591

Cunnane, S. C., Hamadeh, M. J., Liede, A. C., Thompson, L. U., Wolever, T. M. S. \& Jenkins, D. J. A. (1995). Nutritional attributes of traditional flaxseed in healthyyoung adults. American Journal of Clinical Nutrition, 61(1), 62-68.

Devi, P. B., Vijayabharathi, R., Sathyabama, S., Malleshi, N. G. \& Priyadarisini, V. B. (2014). Health benefits of finger millet (eleusine coracana 1.) polyphenols and dietary fiber: A review. Journal of Food Science and Technology-mysore, 51(6), 10211040. doi:10.1007/s13197-011-0584-9

Hegde, P. S., Anitha, B. \& Chandra, T. S. (2005). In vivo effect of whole grain flour of finger millet (eleusine coracana) and kodo millet (paspalum scrobiculatum) on rat dermal wound healing. Indian Journal of Experimental Biology, 43(3), 254-258.
Janghu, S., Ray, A., Bansal, V. \& Kaushik, R. (2014). Dehydration process optimization for maximum lycopene retention in tomato slices using response surface methodology. Asian Journal of Dairy and Food Research, 33(3), 204-208.

Kaushik, R., Chawla, P., Kumar, N., Janghu, S. \& Lohan, A. (2018). Effect of premilling treatments on wheat gluten extraction and noodle quality. Food Science and Technology International, 24(7), 627-636. PMID: 29911411. doi:10.1177/1082013218782368

Kaushik, R., Chawla, P., Kumar, N. \& Kumar, M. (2017). Effect of pre-milling treatments on wheat flour quality. Annals of the University Dunarea De Jos of Galati, Fascicle Vi-food Technology, 41(2), 141-152.

Kaushik, R., Sachdeva, B. \& Arora, S. (2014). Heat stability and thermal properties of calcium fortified milk. Cyta - Journal of Food, 13(2), 305-311. doi:10 . 1080/ 19476337.2014 .971346

Kaushik, R., Sharma, N., Swami, N., Sihag, M., Goyal, A., Chawla, P., ... Pawar, A. (2013). Physico-chemical properties, extraction and characterization of gluten from different indian wheat cultivars. $R e$ search \& Reviews: A Journal of Crop Science and Technology, 2, 37-42.

Kumar, N., Khatkar, B. S. \& Kaushik, R. (2013). Effect of reducing agents on wheat gluten and quality characteristics of flour and cookies. Annals of the University Dunarea de Jos of Galati Fascicle VI - Food Technology, 37(2), 68-81. Retrieved from http:// search.ebscohost.com/login. aspx? direct= true \& AuthType $=\mathrm{ip}$, uid \& db=bth\& $\mathrm{AN}=$ $95805839 \&$ site $=$ eds - live $\&$ scope $=$ site $\&$ authtype=ip, cookie, uid

Liu, D. S., Bates, C. J., Yin, T. A., Wang, X. B. \& Lu, C. Q. (1993). Nutritional efficacy of a fortified weaning rusk in a rural area near beijing. American Journal of Clinical $\mathrm{Nu}$ trition, 57(4), 506-511.

Lue, S., Hsieh, F. \& Huff, H. E. (1991). Extrusion cooking of corn meal and sugar-beet fiber effects on expansion properties, starch gelatinization, and dietary fiber content. $\mathrm{Cer}$ eal Chemistry, 68(3), 227-234. 
Mallik, J. \& Kulkarni, S. (2010). Quality of rusks prepared by incorporation of concentrated whey. Journal of Food Science and Technology-mysore, 47(3), 339-342. doi:10. 1007/s13197-010-0055-8

Miremadi, F., Sherkat, F. \& Stojanouska, L. (2016). Hypocholesterolaemic effect and anti-hypertensive properties of probiotics and prebiotics: A review. Journal of Functional Foods, 25, 497-510. doi:10.1016/j.jff. 2016.06.016

Nasirullah, Marry, S. R. J. \& Shariff, R. (2013). Studies on the trans-fatty acids and the stability of the fats present in indian bakery products. Grasas Y Aceites, 64(1), 36-40. doi:10.3989/gya.058812

Official Methods of Analysis of the Association of Official Analytical Chemists. (2012). North fredrick avenue gaithersburg, maryland, usa. Retrieved from https:// www . aoac . org / official - methods - of - analysis 19th-edition-2012/\#

Pohjanheimo, T. A., Hakala, M. A., Tahvonen, R. L., Salminen, S. J. \& Kallio, H. P. (2006). Flaxseed in breadmaking: Effects on sensory quality, aging, and composition of bakery products. Journal of Food Science, 71(4), S343-S348. doi:10.1111/j . 1750-3841.2006.00005.x

Ranganna, S. (1986). Handbook of analysis and quality control for fruit and vegetable products. Tata McGraw-Hill. Retrieved from https://books.google.pt/books?id= jQN8Kpj0UOMC

Ratnayake, W. M. N., Behrens, W. A., Fischer, P. W. F., Labbe, M. R., Mongeau, R. \& Bearerogers, J. L. (1992). Chemical and nutritional studies of flaxseed (variety linott) in rats. Journal of Nutritional Biochemistry, 3(5), 232-240. doi:10.1016 / 0955 2863(92)90045-K

Rupasinghe, H. P. V., Wang, L., Huber, G. M. \& Pitts, N. L. (2008). Effect of baking on dietary fibre and phenolics of muffins incorporated with apple skin powder. Food Chemistry, 107(3), 1217-1224. doi:10.1016/j . foodchem.2007.09.057

Sharma, N., Khatkar, B. S., Kaushik, R., Sharma, P. \& Sharma, R. (2017). Isolation and development of wheat based gluten ed- ible film and its physicochemical properties. International Food Research Journal, $24(1), 94-101$.

Singh, B. \& Singh, N. (2006). Physico-chemical, water and oil absorption and thermal properties of gluten isolated from different indian wheat cultivars. Journal of Food Science and Technology Mysore, 43(3), 251255. Retrieved from https:// eurekamag. com/research/004/460/004460147.php

Supekar, D. T., Patil, S. R. \& Munjal, S. V. (2005). Comparative study off some important aestivum, durum and dicoccum wheat cultivars for grain, flour quality and suitability for chapati making characteristics. Journal of Food Science and Technology - Mysore, 42(6), 488-492.

Williams, D. A. (1976). Rusk based food snack. US Patent 3,989,858. Google Patents.

Yaseen, A. A. E. (2000). Formulating a new high fiber rusk for production on commercial scale. Nahrung-food, 44(2), 110-113. doi:10 . 1002 / (SICI ) 1521 - 3803(20000301) 44:2〈110::AID-FOOD110〉3.0.CO;2-2 